\title{
Yaratıcı Endüstriler, Kültür Temelli Girişimcilik ve Eleştirel Ekonomi Politik: Kör Noktayı Yeniden Düşünmek
}

\author{
SERHAT KAYMAS* \\ ahmetserhat.kaymas@windowslive.com \\ ORCID ID: 0000-0003-4096-1546
}

\begin{abstract}
Öz: Bu çalışma, yaratıcı endüstriler içerisinde dönüşsen kültür temelli girişimciliği, Türkiye’nin yaratıcı ekosistemi içerisinde yeniden düşünmeyi amaçlamıştır. Yaratıcı yayılım ve kültürel coğrafya teorilerine dayanan çalışma içerisinde, kültür temelli girişimcilik Türkiye’nin bilgi toplumuna dönüşüm süreci içerisinde tartışılmaktadır. Kapitalizmin yakın döneminde, kültür temelligirişimciliğin, ticari biryatırımcılık olarak okunmasından daha çok, ülkelerin yenilikçilik ă̆ının önemli bir bileşeni olarak ele almayı amaçlayan bu çalışmada, Ankara, İstanbul ve İzmir olmak üzere Türkiye’nin yaratıcı ekosistemi içerisinde farklı kesitleri temsil eden üç il, araştırmanın uzamı olarak seçilmiştir. İstanbul'un 2010 yılında Avrupa Başkenti olmasının yanı sıra, UNESCO yaratıcı şehirler ağında tasarım kenti olarak yer alması, Ankara'nın ise Türkiye’nin başkenti olmasının yanı sıra bilgi teknolojileri alanında öne çıkması ile İzmir'in yaratıcı kente dönüşüm planları söz konusu kentlerin seçilmesi için önemli bir gerekçe sağlamıştır. Çalışmada, öte yandan, UNESCO ve Avrupa Birliğinin yaratıcı endüstrilerde girişimcilik politikaları karşılaştırmalı siyasa analizi üzerinden değerlendirilmektedir. Çalışmada, Türkiye için alternatif bir dizi yönetişim önerisi geliştirilmiştir.
\end{abstract}

Anahtar kelimeler: Yaratıcı endüstriler, Yaratıcı ekonomi, Kültür temelli girişimcilik, Kültürel coğrafya, Yaratıcı yayılım

\section{Giriş}

Yaratıcı kültür endüstrileri ekosistemi, 1990'lı yılların sonundan itibaren hem bir siyasa hem de bir uygulama alanı olarak "yeniden keşfedilirken”, özellikle gelişmekte olan ülkelerdeki alan yazın içerisinde iki önemli tartışma ekseninin şaşırtıcı ölçüde ihmal edildiği gözlenir. Alan yazın içerisinde sözü edilen ilk kör noktayı, kültür temelli girişimciliğin oldukça sınırlı olarak tartışılması oluşturmaktayken, ikinci eksende kültür temelli girişimciliğin kentlerle kurduğu diyalektiğin nerede ise üzerinin örtülü olarak bırakılmasıdır. Bu çalışmada, alan yazının söz konusu ilgisizliğine dair bir yanıtın, Türkiye'de üç kentin yaratıcı endüstriler ekosistemi ve gelişmekte olan kültür temelli girişimciliği kesitlerinden bakarak verilmesi amaçlanmıştır. Çalışmanın, özetinde de yer verildiği gibi, Ankara, İstanbul ve İzmir kentlerindeki kültür

\footnotetext{
* Doç. Dr., Hacettepe Üniversitesi, İletişim Fakültesi, Radyo, Televizyon ve Sinema Bölümü.
} 
temelli girişimcilik ve kent diyalektiğini, küresel örnekleri ile karşılaştırmalı olarak okumayı amaçlayarak ilerleyen bu çalışma, yeni enformasyon ve iletişim teknolojilerinin refakatinde dönüşen girişimcilik kültürünün kent ile kurduğu diyalektiği aşağıdaki sorular ekseninde tartışmayı amaçlamaktadır. 1) Yeni enformasyon ve iletişim teknolojileri, girişimcilik kültürünü ve girişimcilik kültüründeki egemen değer dizisini nasıl etkilemekte ve dönüştürmektedir? Böylesi bir dönüşüm, yaratıcı endüstriler içerisinde kültürel ekonominin bir bileşeni olarak nasıl değerlendirilebilir?” 2) Ülkelerin bilgi toplumuna dönüşüm süreç ve pratiğinin önemli bir bileşeni olarak yaratıcı ekonomiler içerisinde dönüşen girişimcilik ve kültürü, kentsel uzamlar içerisinde nasıl çözümlenebilir? 3) Yaratıcı kültür endüstrileri ekosistemi içerisinde, kentler tam da bilgi toplumu dönüşüm süreçlerini yaratıcı ekonomilere bağlayan uzamlar olarak nasıl yeniden değerlendirilebilir? Yukarıdaki soruları derinleştirerek Türkiye özelinde tartışmayı ve kültür temelli girişimciliği önemli bir bağlama yerleştirmeyi amaçlayan bu çalışma içerisinde son soru ise 4) “Türkiyede 'kültürel ekonomik coğrafya' ve 'yaratıcı yayılım' yaklaşımları, yeni enformasyon ve iletişim teknolojilerinin refakatinde dönüşen kültürel girişimciliği anlamlandırılabilme adına nasıl kullanılabilir?” olarak belirlenmiştir.

İlerleyen kısımlar içerisinde ayrıntılı olarak değerlendirileceği üzere çalışmanın yanıt aradığı yukarıdaki soruların, önemli bir ikilemi yeniden ziyaret etmek üzerine temellendiği söylenmelidir. İnternet ve bileşen bilgi teknolojilerinin yer edindiği ve edindiği yeri genişlettiği diğer alanlarda olduğu gibi, girişimcilik kültürü üzerindeki yansımaları popüler kültürün söylem repertuarında yeni bir firsatlar alanı olarak temsil edilirken Türkiye'de sürdürülen çalışmalar içerisinde benzeri ya da yakın bir merak uyandıramamış olması söz konusu ikilemi oluşturmaktadır. ${ }^{1}$ Çalışma boyunca, yukarıda yer aldığı üzere ilki kuramsal bir tartışmaya olanak sunması ikincisi ise böylesi bir kurumsal okumanın yaratıcı endüstriler ekosistemi içerisinde bir mikro okuma pratiğine olanak sağlaması için yukarıda yer verilen sorulara, en azından kendi içerisinde, tutarlı ve bütüncül bir yanıtın verilebilmesi amaçlanmıştır.

\section{Yaratıcı Endüstriler Ekosistemi ve Kültürr Temelli Girişimcilik Diyalektiğini Okumak}

Yaratıcı endüstriler ve bileşen yaratıcı ekonomileri yeniden tartışmak, ya da bu alt bölümün başlı̆̆ında yer verildiği üzere yeniden ziyaret etmek, aslında bugüne değin sorulan güçlü bir soruyu farklı bir açıdan düşünmek için önemli bir firsatı oluşturmaktadır. Yaratıcı endüstriler alan yazınına dair en azından alternatif hatta karşıt bir okuma çabası, gerçekte bir ironi olarak da sorulan, "yaratıcı endüstriler içerisinde yeni olan nedir ki?” sorusu ile yeniden yüzleşmek için önemli bir olanak sunmaktadir.

Yukarıda yer alan soruyu, dönüşen girişimcilik kültürünü içerisine alacak denli ge-

1 Türkiye'de kültürel ekonominin bir yansıması olarak internet ve dönüşen yeni iş modellerine dair bütüncül bir tartışmanın henüz Türkiye’de alan yazın için önemli bir ilgisizlikle karşılandığı söylenmelidir. Erkan Saka, "Dijital Dönüşüm ve Gazetecilik İçin Yeni İş Modelleri”, Dijitalleşen Gazetecilik İçin Yeni İş Modelleri, der., Erkan Saka, Vehbi Görgülü ve Anıl Sayan, İstanbul: Taş Mektep Yayınları, 2017, s.11-14. 
nişleterek, yanıtlama çabası değişenin aslında kapitalizmin bizatihi kendisi olduğuna ilk paragrafında yer veren bir cümleyle başlamalıdır. ${ }^{2}$ Gerçekten de yaratıcı endüstriler, en azından bir fısıltı olarak, kapitalizmin bütün bir üretim ilişkilerinin, üretici güçlerinin ve üretim kapasitesinin değiştiğini bir adım sonrasındaysa ülkelerin bütün bir kalkınmasına dair değerler zincirinin köklü bir değişimin eşiğinde olduğunu söylemektedir. O denli ki, 1970'li yıllara değin ağır sanayi ve fabrikalar ekseninde belirginleşen ulusal ekonomilerin taşıyıcı kolonlarının köklü bir değişiminin eşiğine gelmesi, yalnızca, on yıl sürmüştür. Üretim ilişkileri içerisinde bilginin kendisine önemli bir yer açması ve açtı̆̆ı yeri de genişletmesine koşut olarak ${ }^{3}$ yeniden keşfedilen, gerçekte de ise ilerleyen kısımlar içerisinde ele alınacağı gibi zaten var olan, yaratıcı endüstriler sözü edilen dönüşümün üretim ilişkileri içerisinde bilginin kentsel dönüşümlere taşındığı kültürel simgesini oluşturmaktadır. Kapitalizmin, her ne kadar, bütün bir tarihi aslında ulusal ekonomilerin kurulmasına paralel bir anlatı olarak kentler ve kentsel kalkınma süreçlerinden bağımsız değilse de yaratıcı endüstriler ekosistemi içerisindeki vurgunun kapitalist birikimin kentlerle kurduğu diyalektik üzerine olduğu söylenmelidir.

Bilişsel kapitalizmin yeni, “yaratıcı”, sınıf ile mekân bağının kurulması tam da işaret edilen anlatının içeriğini anlamlı bir biçimde dokumaktadır. Bu doğrultuda, yukarıda sözü edildiği üzere kültürel ekonomik coğrafya ve yaratıcı yayılım yaklaşımları tam da değişen sosyal uzamlar içerisinde kapitalizmin kendisini yeni uğraklarında nasıl da yeniden üretebildiği sorusuna güçlü bir yanıt sunmaktadır. O denli ki, erken dönemli tartışmalarından itibaren ${ }^{4}$ bilgi toplumuna geçiş ve dijital dönüşümün önemli bir uzamı olarak kentlerin ancak yaratıcı endüstriler ekosisteminin önemli bir bileşeni olarak yaratıcı sınıfı kendisine çeken mekânları oluşturduğu belirtilir.

Yaratıcı sınıfın önemli bir bileşeni olarak, "yaratıcı” girişimcilerin kentlerin kapitalizmin yeni birikim koşulları içerisinde anlamlı işlevleri bulunmaktadır. Ancak küresel alan yazın içerisinde yaratıcı girişimciliği değerlendirme pratiğinin üç önemli unsuru bulunmaktadır. İlk eksen, yaratıcı fikirlerin yaratıcı metalara nasıl dönüştürüldüğünü bu doğrultuda girişimcilerin söz konusu ekosistem içerisindeki tutumlarının nasıl kurulduğunu ve sürdürüldüğünü araştırma nesnesi olarak belirlemiştir. ${ }^{5}$ Yaratıcı girişimciliği değerlendirmenin diğer ekseni, Lorenzo, Donnely, Trujilo ve

\footnotetext{
$2 \mathrm{Bu}$ doğrultuda ayrıntılı bir tartışma için, Joachim Thiel, "Creative Cities and the Reflexivity of the Urban Creative Economy”, European Urban and Regional Studies, 24/1 (2017), s.21-34.

3 Bilgi Toplumu söylemi, en azından alan yazını içerisinde 1970'li yıllardan bu yana sosyal bilimlerin araştırma ilgisi içerisinde güçlü bir ilgi sunmaktadır. Alain Touraine, The Post-Industrial Society: Tomorrow's Social History: Classes, Conflicts and Culture in the Programmed Society, London: Wildwood House, 1974 ve Daniel Bell, The Coming of Post-İndustrial Society London: Heinemann, 1974 aktaran Christian Fuchs, "Kapitalizm mi? Enformasyon Toplumu mu?”, Dijital Emek ve KarlMarx, der., Christian Fuchs, çev., Tahir Emre Kalaycı ve Senem Oğuz, Ankara: NotaBene Yayınları, 2015, s.207.

4 Bu açıdan Richard Florida’nın tartışması anlamlı bir tartışma uzamı açmıştır, bkz. Richard Florida, The Rise of Creative Class: Revisited, New York: Basic Books, 2014, s.205-208. Öte yandan Kerrigan ve Hutchinson'in çalışması yukarıdaki tartışmanın refakatinde önemli bir okuma olanağı sunmaktadır, bkz. Susan Kerrigan and Samuel Hutchinson, "Regional Creative Industries: Transforming the Steel City into a Creative City in Newcastle, Australia”, Creative Industries Journal, 9/2 (2014), s.119.

5 V. Pawan Bhansing, Erik Hitter ve Yosha Winjgarden, "Passion Inspires: Motivations of Creative Entrepreneurs in Creative Business Centers in the Netherlands", The Journal of Entrepreneurship, 27/1 (2019), s.1-24.
} 
Imas’ın ${ }^{6}$ sözünü ettiği üzere, yaratıcı girişimlerin daha geniş ölçekte çevreleri ve kurumsal bağlamlarla olan etkileşimini değerlendirmektir. Bununla birlikte söz konusu her iki eksenin bir dizi soruna sahip olduğu en azından bu çalışmanın yazarı tarafından öne sürülmektedir.

$\mathrm{Bu}$ çalışmanın eklemlendiği üçüncü eksen içerisinde ise, yaratıcı ya da bilgi temelli kapitalizm içerisinde kentlerin bilgi ve bireysel yetenekler, yaratıcılık ve fikri hakların kullanılması üzerinden genişleyen girişimler için nasıl bir olanak ya da kısıt sunduğu araştırılmaktadır. Bu doğrultuda da mekânın sosyal inşasının yanı sıra kapitalizmin yeni koşulları içerisinde üretim ve tüketimin ağırlıklı olarak gerçekleştiği kentsel uzamların bilgi temelli kapitalizm ile kurduğu diyalektik üzerinden çözümleyebilmek anlamlı bir bütünlük sağlamaktadır. Bu doğrultuda, henüz giriş kısmında da yer aldığı üzere, Türkiye'nin yaratıcı ekonomi bileşenleri içerisinde farklı unsurları ile öne çıkan Ankara, İstanbul ve İzmir bu çalışmanın araştırma uzamını oluşturmaktadır. Ancak bu tartışmayı genişletmeden önce önemli bir unsurun belirginleştirilmesi gerekmektedir. Çalışma içerisinde kentsel uzamlar, daha önce de değinildiği üzere, ülkelerin birikim modellerindeki makro yapısal değişim kesitlerinde bir girişimcilik uzamı olarak ele alınmaktadır. Bu yönüyle kentler, özellikle Türkiye’de oldukça sınırlı bir tartışmanın odağında yer edinebilmiştir. Gelişmiş ülkelerden farklı olarak, gelişmekte olan ülkelerin bilişsel kapitalizm uğrağı içerisindeki yapısal değişimlerinin okunabileceği önemli bir uzamın tam da kentler ekseninde açıldığını “öngören” bu çalışma içerisinde kültürel girişimcilik Türkiye’nin bilişsel kapitalizm dönemi içerisinde ele alınmaktadır.

Bilgi toplumu dönüşümlerini insani sermayeye eklemleyen yaratıcı endüstrilerin bileşeni olarak yaratıcı ekonomileri anlamlandırma adına hem sözü edilen bilişsel ekonomiler içerisinde önemli bir uygulama alanı açtığı hem de sağladı̆̆ı refah ve istihdam potansiyeli üzerinden kayda değer bir siyasa alanı olarak yükseldiği belirtilmelidir. ${ }^{7}$ Bununla birlikte, henüz derinlemesine bir tartışmaya geçilmeden önce, yaratıcı endüstrileri odağına alan araştırmalara dair genel bir değerlendirmenin yapılması ve bu çalışmanın alan yazına katkısının belirtilmesi doğru olacaktır. Yaratıcı endüstrilerin küresel olarak istihdam ve refahın yeni kaynakları olarak değerlendirilmesine rağmen, geniş bir uzama yayılan "yaratıcı ekonomilerin” ağırlıklı olarak gelişmiş Avrupa / Amerikan “anakent” merkezlerini odağına alması ${ }^{8}$ ancak gelişmekte olan ülkeleri gittikçe ikincil kılması, en azından, bir eşitsizlik olarak eleştirilmesi gerekir.

Yaratıcı endüstriler ve bileşen yaratıcı ekonomi içerisinde ikinci eleştiri ekseni, özellikle gelişmekte olan ülkeler ve yaratıcı girişim potansiyellerinin gerek ülkelerin kültür politikaları ve gerekse bir araştırma nesnesi olarak akademik tartışmalar içerisinde oldukça sınırlı bir ilginin odağında yer edinebilmesidir. Bu doğrultuda

6 Lucia Garcia Lorenzo vd., "Liminal Entrepreneuring: The Creative Practices of Nascent Necessity Entrepreneurship", Organization Studies, 39/2-3 (2018), s. 373-395.

7 Jadranka Svarc, “The Knowledge Worker is Dead: What About Professions?”, Current Sociology, 64/3 (2016), s.392-410. Öte yandan kapsamlı bir tartışma için bu çalışmanın yazarının önceki çalışmaları da dikkate alınmalıdır.

8 Ana Alacovska ve Rosalind Gill, "De-Westernizing Creative Labour Studies: The Informality of Creative Work from an Ex-Centric Perspective”, International Journal of Cultural Studies, 22/2 (2019), s.195-212. 
Türkiye'nin yaratıcı endüstriler ve bileşen alt alanlarını odağına alan ayırt edilebilir bir kültür politikasına sahip olmaması en azından şaşırtıcıdır. Ancak yukarıda da belirtildiği üzere, yaratıcı kültür endüstriler aslında kültür politikalarının yeniden güç kazanmasına dair önemli bir ekosistem oluşturmuştur. Ülkelerin tam da bilgi toplumuna dönüşüm süreçlerine eşlik eden "kültür politikaları" kavrayışı Hesmondhalgh, Oakley, Lee ve Nisbett 'in’ belirttiği gibi yaratıcı endüstrileri ve yaratıcı ekonomileri odağına alırken ülkelerin kültür politikalarına dair beklentilerinin yeniden biçimlendiği bir dönemi oluşturmaktadır.

Kültür politikalarının yeni döneminin, Avrupa Birliğìnin “Creative Europe” programında olduğu üzere kültürel üretimin ve yaratıcı endüstriler sektörünün desteklenmesi ya da Güney Kore’de, Korean Wave, olduğu üzere ülkenin bir marka değeri alması gibi bileşenlere sahip olduğu söylenmelidir. ${ }^{10} \mathrm{Bu}$ açıdan diğer ülkelerin siyasa gelenekleri doğrultusunda farklı eğilimler izlediği belirtilmelidir. Örneğin Amerika Birleşik Devletleri yaratıcı kültür endüstrileri ekosistemi içerisinde vergi avantajları sunarak "kolaylaştırıcı devlet" rolünü üstlenirken, İngiltere gerçekleştirdiği politikalar üzerinden bir "himayeci devlet” işlevini üstlenmişken, Fransa bürokrasisi eliyle yaratıcı kültür endüstrilerini desteklemektedir. Art alanında önemli bir "sosyalizm" deneyimine sahip olan Çin Halk Cumhuriyeti ise söz konusu ekosistem içerisinde "sert” olarak tanımlanan bir kontrol devleti statüsünü üstlenmiştir.

Türkiye’nin ise en azından alanda gerçekleştirilen araştırmalar için düzenli olarak güncellenen veri kaynaklarının olmaması, bu çalışmada da olduğu üzere, araştırma verilerinin Birleşmiş Milletler Ticaret ve Kalkınma Kongresi ya da Eurostat gibi Avrupa Birliği tarafından üretilen veriler üzerinden sağlanması zorunluluğunu gerektirmektedir. Yine bir diğer önemli sorunun ise, Türkiye’de yaratıcı kültür endüstrilerini odağına alan çalışmaları kuramsal bir tartışmanın ötesine çoğu kez taşıyamamakta ve alan yazının önemli sınırlarla çevrili olmasına yol açmaktadır. ${ }^{11}$ Ancak yukarıda da değinildiği üzere, Türkiye'nin bu alandaki önemli bir diğer sorunu, dönüşen girişimcilik kültürünü ve potansiyelini, tıpkı ayırt edici bir siyasa geliştiremediği gibi, sürdürülebilir bir kalkınma içerisinde kullanamamasıdır.

\section{Yaratıcı Endüstriler, Dönüşen Ekonomiler ve Girişimcilik Kültüüüne Yeni Bir Ziyaret}

Birleşmiş Milletler Ticaret ve Kalkınma Kongresi’nin ${ }^{12}$ değerlendirdiği üzere, bilgi

9 David Hesmondhalgh vd., Culture, Economy and Politics: The Case of New Labour, Basingstoke, Hampshire: Palgrave \& McMillan Publications, 2015, s.154.

10 Dal Yong Jin, New Korean Wave: Transnational Cultural Power in the Age of Social Media, Chicago, Springfield: University of Illinois Press, 2016, s.150.

$11 \mathrm{Bu}$ açıdan her ne kadar Türkiye’de akademik olarak önemli bir ilgi uyanmış olsa da yukarıda sözü edilen unsurlar nedeni ile oldukça keskin bir dizi sorun ile karşılaşıldığı söylenmelidir. Bkz. Serhat Kaymas, "Yaratıcı Endüstriler Ekosistemi İçerisinde Ankara: Sorunlar, Olanaklar ve Potansiyeller Üzerine Bir Değerlendirme”, Ankara Üniversitesi Sosyal Bilimler Enstitüsü Dergisi, 10/2 (2019), s.110; Lazeretti, Luciana, Francesko Capone ve Erdem Seçilmiş, "In Search of a Mediterranean Creativity: Cultural and Creative Industries in Italy, Spain and Turkey", European Planning Studies, 24/3 (2016), s.571; Seungil Yum, “The Relationship Between Creative Industries and the Urban Economy in the USA", Creative Industries Journal, 13/2 (2020), s.2.

12 UNCTAD, "Creative Economy Outlook: Trends in International Trade in Creative Industries: 2002-2015", erişim 18 Ekim, 2020, https://unctad.org/system/files/official-document/ditcted2018d3_en.pdf. 
temelli kapitalizmin önemli bir bileşeni olarak yaratıcı girişimcilik gittikçe kentleri dönüştürme potansiyeli gösterirken yaratıcı ekonomileri kentlere bağlayan önemli bir bileşen olarak girişimciliğin yaratıcılık, kültür, ekonomi ve teknolojinin ara yüzeylerindeki rolü, genellikle, ikincil kalmaktadır. Bu açıdan henüz yeni ekonomilerin kentlerle kurduğu diyalektiğin geniş kapsamlı çözümlemesine geçilmeden, yaratıcı endüstrilerde girişimcilik ve böylesi bir girişimciliğin geleneksel girişimciliğe göre farklılıklarının, en azından genel olarak, tartışılması doğru olacaktır.

Yaratıcı kültür endüstrileri ekosistemi içerisinde girişimcilik kavrayışına dair daha genel bir tartışmaya geçilmesinin öncesinde kavramın etimolojisi ve yaratıcı ekonomiler içerisinde yer edinmesi ile ilgili genel bir açıklamanın yapılması anlamlı olacaktır. İngilizceye Fransızcadan devşirilen "entrepreneur" sözcüğü, 17. yüzyıl boyunca, bir işi bir projeyi ya da bir aktiviteyi üstlenen kişiyi tanımlamak için Fransız ekonomistler tarafından yaygın olarak kullanılmıştır. 19. yüzyıl ise girişimci teriminin en azından Fransız iktisat bilimcisi Jean Baptiste Say tarafından genişletilen anlamı ${ }^{13}$ ile yeni bir anlam edindiği yüzyılı oluşturur. Girişimcinin, ekonominin kıt kaynaklarını yüksek üretim içerisinde biçimlendiren kişi olarak değerlendirilmesi bu açıdan önem taşımaktadır. Yaratıcı endüstriler içerisinde girişimcilik boyutu ise kelimenin asıl anlamına sadık kalınarak tanımlanmakta olup, girişimcinin aslında ekonomik değerleri yarattı̆̆ belirtilmiştir.

Girişimciliğin, ekonomik değeri yaratan ve piyasa ilişkileri içerisinde yeni bir meta üretimi için yeni üretim ilişkilerini geliştiren kişi olmasının dışında ortak bir tanımının tarih boyunca geliştirilmemiş olmasına, hatta böylesi bir çabanın alan yazın içerisinde sınırlı olarak yer edinmiş olmasına rağmen, bu açıdan bir dizi çabanın olduğu söylenebilir. Sakura Yamumura ve Paul Laselle’in belirttiği üzere ${ }^{14}$, ekonominin bileşenleri içerisinde bir tutarlılık ve kültürel bütünlük oluşturan "yaratıcı" bir aktör olarak değerlendirmesi girişimcinin anlamlandırılması için en azından bir olanağı oluşturmaktadır. Gerçekten de girişimcinin, yukarıda yer aldığı üzere kendi ekosistemini kendi eliyle kuran bir “özne” olarak değerlendirilmesi ve bu yönüyle de oldukça geniş bir uzamı içeren yaratıcı kültür endüstrilerinin merkezinde yer almasının bir dizi güçlü nedeni bulunmaktadır. Girişimciliğin geleneksel biçimlerinden yaratıcı biçimlerine doğru geçiş sürecinin önemli bileşenlerinden birisinin girişimcilik ve yenilikçilik tartışması üzerinde kurulduğu görülür. Adriana Bujor ve Silvia Avasilcai ${ }^{15}$ ise, iktisat yazını içerisinde girişimciliğe dair erken dönemli tartışmaların ardından, Joseph Schumpeter'in “yaratıcı yıkım” yaklaşımıyla birlikte girişimcinin de bir yenilikçi olarak değerlendirilmesi gerektiğine dair uzlaşının kurulduğunu belirtir.

13 HKU, The Entrepreneurial Dimensions of the Cultural and Creative Industries, Utrecht: Hogerschool vor de Kunsten Publications, 2010.

14 Yamamura Sakura ve Paul Laselle, "Proximities and the Emergence of Regional Industry: Evidence of the Liability of Smallness in Malta”, European Planning Studies, 28/2 (2019), s.380-399.

15 Bujor Adriana ve Silvia Avasilcai, "Creative Entrepreneurship in Europe: A Framework of Analysis", Annals of the Oradea University: Fascicle of Management and Technological Engineering, 1 (2014), s.151-156. 
Yaklaşım, girişimcinin organizasyonel ya da kurumsal yeterliliğinden daha çok bireysel tutumlarını yansıtacak denli kullanılmasına rağmen bizatihi Schumpeter'in ifadelerinde yer aldığ yapısı içerisinde devrim ya da yenilenme gerçekleştirmesidir” ${ }^{16} \mathrm{Bu}$ süreç içerisinde girişimciye, gelişmeyi belirli bir denge çizgisinin aşılması ve yeni bir dengenin kurulması için merkezi bir rol atfeden Schumpeter'in belirttiği üzere, böylesi bir yaratıcı yıkımın gerçekleştirilebilmesinin tam da girişimci tarafından üstlenilebilecek temel bileşenleri bulunmaktadır. Örneğin, yeni pazarların bulunması, örgütsel düzenlemenin yeni biçimlerinin uygulaması ya da teklif edilmesi, yeni üretim yöntemlerinin uygulanması, hammadde ve mamul üretim için yeni kaynakların oluşturulması ya da keşfedilmesi, yeni ya da yenilikçi metaların geliştirilmesi girişimcinin işlevlerini oluşturmaktadır.

Yaratıcı kültür endüstrileri ekosistemi söz konusu olduğunda ise girişimciliğin sözü edilen işlevlerinin nerede ise bir önkoşul olarak öne çıktığ belirtilmelidir. O denli ki, "entelektüel sermayenin" maddi olmayan emek biçimi olarak bütün bir üretim ilişkileri ağı içerisindeki yeri genişledikçe ${ }^{17}$, yaratıcı endüstriler ekosistemi içerisinde girişimciliğin merkezi bir unsura dönüşmesi oldukça anlaşılırdır. Ancak, yaratıcı endüstriler ekosistemi içerisinde girişimciliğin önemli boyutlarından birisi bu yöndeki bir çabanın tam da kent ekonomileri ya da kent soylu üretim ilişkileri aksları boyunca sürmesidir. Aşağıda yaratıcı kültür endüstrileri ekosisteminin uzamı hakkında en azından genel bir fikir verebilmek ile söz konusu ekosistemin "kentli" niteliğini vurgulayabilmek amacı ile Tablo 1 içerisinde yer almaktadır. ${ }^{18}$

Tablo 1'in sunumuna geçilmeden önce bir dizi niteliğinin vurgulanması doğru olacaktır. Bu doğrultuda üç ana unsur özel olarak önem taşımaktadır. 1) Yaratıcı ekonomiler için önemli bir bağlam oluşturan yaratıcı endüstriler ekosistemi, Tablo 1 içerisinde de görülebileceği üzere birbiri ile kolaylıkla bağdaşmayacak gibi görünen endüstri bileşeninden oluşmaktadır. Örneğin geleneksel kültürel ifadeler, kukla tiyatrosu vb. ile bilgisayar programları ya da bilgisayar yazılımları ile mimari örneğinde olduğu üzere. 2) Ancak böylesi bir geniş uzam yaratıcı endüstriler ve bileşenlerinin daha çok bireysel yetenekler ve girişim kapasitesi üzerinden yaratıcı ekonomiler içerisinde yer edinebilme niteliğine sahiptir. 3) Aşağıda yer alan yaratıcı endüstriler, Tablo kaynakçasında da yer aldığı üzere ülkelerin ya da ulus üstü kuruluşların seçimlerini yansıtmaktadır. Post Fordist servis ekonomileri içesinde endüstrilerin farklı açılardan da ele alındığı belirtilmelidir. Bununla birlikte aşağıda yer alan Tablo, yaratıcı endüstrileri geniş bir uzam içerisinde değerlendirme potansiyeline sahiptir. Tür-

16 Tiryakioğlu’nun değerlendirdiği üzere, kapitalizmi kendi kendisini yenileyen statik bir akım tablosu içerisinden ele almak yerine dinamik bir gelişme tablosu içerisinde kapitalizmin kendisini yeniden ürettiğini belirtmiştir. Murad Tiryakioğlu, "Schumpeter, Yenilik ve Yaratıcı Yıkım”, İktisadiyat, 18.03.2009, çevrimiçi: http://www.iktisadiyat.com/2009/03/18/schumpeter-yenilik-ve-yaratici-yikim/.

17 Hye-Kyung Lee, “The Political Economy of Creative Industries”, Media, CultureðSociety, 39/7 (2017), s.1080. 18 Yaratıcı endüstrilerin sınıflandırılmasına dair farklı örneklerin de olduğu söylenmelidir. David Throsby, çalışmasında, yukarıdaki sınıflandırmanın yanı sıra Amerika Birleşik Devletleri’nde, "Americans for the Arts Model" isimli bir modele yer vermekte ve sözü edilen modelin ticari girişimlerle bütünleşmiş bir sanat algısını öne çıkarttı̆̆ını belirtmektedir. David Throsby, "Modelling the Cultural Industries", International Journal of Cultural Policy, 14/3 (2008), s.221. 
kiye’de alan yazın içerisinde de yaygın olarak kabul edilen ve alan yazın içerisinde uzlaşı sağlayan bir boyutu da olduğu için kullanılmaktadır.

Tablo 1. Yaratıcı Endüstriler Ekosistemi ve Sinıflandırmasi ${ }^{19}$

\begin{tabular}{|c|c|c|c|c|c|}
\hline \multicolumn{6}{|c|}{ Yaratıcı Kültür Endüstrileri Ekosistemi Sınıflandırması } \\
\hline $\begin{array}{l}\text { Birleşmiş } \\
\text { Milletler Ticaret } \\
\text { ve Kalkınma } \\
\text { Kongresi } \\
\text { (UNCTAD) }\end{array}$ & $\begin{array}{l}\text { İngiltere } \\
\text { Dijital, Kültür } \\
\text { Medya ve } \\
\text { Spor Genel } \\
\text { Müdürlüğ̈̈ } \\
\text { (DCMS) }\end{array}$ & $\begin{array}{l}\text { Sembolik } \\
\text { Metin } \\
\text { Modeli }\end{array}$ & $\begin{array}{l}\text { Eş Merkezli } \\
\text { Çemberler } \\
\text { Modeli }\end{array}$ & $\begin{array}{l}\text { Dünya Fikri } \\
\text { Haklar } \\
\text { Örgütü } \\
\text { (WIPO) } \\
\text { Telif Hakları } \\
\text { Modeli }\end{array}$ & UNESCO \\
\hline $\begin{array}{l}\text { KÜLTÜREL } \\
\text { MİRAS } \\
\text { Geleneksel } \\
\text { Kültürel İfadeler } \\
\text { Zanaatlar } \\
\text { Festivaller } \\
\text { Kutlamalar } \\
\text { Kültürel Siteler } \\
\text { Tarihsel Anıtlar } \\
\text { Müzeler } \\
\text { Kütüphaneler } \\
\text { Arşivler vb. } \\
\text { SANATLAR } \\
\text { Görsel Sanatlar } \\
\text { Resim } \\
\text { Heykel } \\
\text { Antika } \\
\text { Fotoğraf vb. } \\
\text { Performans } \\
\text { Sanatları } \\
\text { Canlı Müzik } \\
\text { Tiyatro } \\
\text { Dans } \\
\text { Opera } \\
\text { Kukla } \\
\text { Sirk vb. } \\
\text { MEDYA } \\
\text { Basılı Medya ve } \\
\text { Yayıncılı } \\
\text { Kitaplar } \\
\text { Gazeteler } \\
\text { Basın } \\
\text { Diğer Yayıncllı }\end{array}$ & $\begin{array}{l}\text { Reklamcılık } \\
\text { Mimari } \\
\text { Sanat ve } \\
\text { Antika Pazarı } \\
\text { Zanaatlar } \\
\text { Tasarım } \\
\text { Moda } \\
\text { Film ve Video } \\
\text { Müzik } \\
\text { Performans } \\
\text { Sanatları } \\
\text { Yazılım } \\
\text { Radyo ve } \\
\text { Televizyon } \\
\text { Video ve } \\
\text { Bilgisayar } \\
\text { Oyunları }\end{array}$ & $\begin{array}{l}\text { Merkezi } \\
\text { Kültür } \\
\text { Endüstrileri } \\
\text { Reklamcılık } \\
\text { Film } \\
\text { İnternet } \\
\text { Müzik } \\
\text { Yayıncılık } \\
\text { Radyo ve } \\
\text { Televizyon } \\
\text { Video ve } \\
\text { Bilgisayar } \\
\text { Oyunları } \\
\\
\text { Çevresel } \\
\text { Kültür } \\
\text { Endüstrileri } \\
\text { Yaratıcı } \\
\text { Sanatlar } \\
\\
\text { Sinırdaki } \\
\text { Kültür } \\
\text { Endüstrileri } \\
\text { Tüketici } \\
\text { Elektroniği } \\
\text { Moda } \\
\text { Bilgisayar } \\
\text { Yazılımı } \\
\text { Spor }\end{array}$ & $\begin{array}{l}\text { Merkezi } \\
\text { Yaratıcı } \\
\text { Sanatlar } \\
\text { Edebiyat } \\
\text { Müzik } \\
\text { Performans } \\
\text { Sanatları } \\
\text { Görsel } \\
\text { Sanatlar } \\
\\
\text { Diğer Merkezi } \\
\text { Kültür } \\
\text { Endüstrileri } \\
\text { Film } \\
\text { Müzeler ve } \\
\text { Kütüphaneler } \\
\\
\text { Geniş Ölçekli } \\
\text { Kültürr } \\
\text { Endüstrileri } \\
\text { Kültürel } \\
\text { Miras } \\
\text { Hizmetleri } \\
\text { Yayıncllık } \\
\text { Ses Kaydı } \\
\text { Radyo ve } \\
\text { Televizyon } \\
\text { Video ve } \\
\text { Bilgisayar } \\
\text { Oyunları }\end{array}$ & $\begin{array}{l}\text { Merkezi } \\
\text { Telif Hakları } \\
\text { Endüstrileri } \\
\text { Reklamcılık } \\
\text { Koleksiyon } \\
\text { Toplulukları } \\
\text { Film ve Video } \\
\text { Müzik } \\
\text { Performans } \\
\text { Sanatları } \\
\text { Yayıncılık } \\
\text { Yazılım } \\
\text { Radyo ve } \\
\text { Televizyon } \\
\text { Görsel } \\
\text { ve Grafik } \\
\text { Sanatları } \\
\\
\text { Bağımsız } \\
\text { Telif Hakları } \\
\text { Endüstrileri } \\
\text { Boş Kayıt } \\
\text { Malzemeleri } \\
\text { Tüketici } \\
\text { Elektroniği } \\
\text { Müzikal } \\
\text { Enstrümanlar } \\
\text { Sayfa } \\
\text { Fotokopileri } \\
\text { Fotoğraf } \\
\text { Malzemeleri }\end{array}$ & $\begin{array}{l}\text { Merkezi } \\
\text { Kültürel } \\
\text { Uzamdaki } \\
\text { Endüstriler } \\
\text { Müzeler, } \\
\text { Galeriler, } \\
\text { Kütüphaneler } \\
\text { Performans } \\
\text { Sanatları } \\
\text { Festivaller } \\
\text { Görsel Sanat } \\
\text { ve Zanaatlar } \\
\text { Tasarım } \\
\text { Yayıncllı } \\
\text { Radyo ve } \\
\text { Televizyon } \\
\text { Film ve Video } \\
\text { Fotoğraf } \\
\text { Etkileşimli } \\
\text { Medya } \\
\\
\text { Genişleyen } \\
\text { Kültürel } \\
\text { Uzamdaki } \\
\text { Endüstriler } \\
\text { Müzikal } \\
\text { Enstrümanlar } \\
\text { Ses Cihazları } \\
\text { Mimari } \\
\text { Reklamcılık }\end{array}$ \\
\hline
\end{tabular}

19 Araştırmacı tarafından derlenmiştir (UNCTAD, 2019; Gov.Uk., "Creative Industries Economic Estimates", 2019, http://www.gov.uk/collections/creativeindustrieseconomicestimates; Throsby, "Modelling the Cultural”; WIPO, "How to Make a Living in the Creative Industries?", Geneva, 2017. (erişim 18.10.2020); UNESCO, Creative Economy Report 2013 Special Edition: Widening Local Development Pathways, New York, Paris: United Nations Development Programmes Publication, 2015). 


\begin{tabular}{|c|c|c|c|}
\hline $\begin{array}{l}\text { Görsel İşitsel } \\
\text { Yayıncılık } \\
\text { Film } \\
\text { Televizyon ve } \\
\text { Radyo Yayıncılığı } \\
\text { Yeni Medya } \\
\text { Dijital İçerik } \\
\text { Yazılım } \\
\text { Video Oyunları } \\
\text { Animasyonlar } \\
\text { vb. } \\
\text { İşlevsel Yaratıcılık } \\
\text { Tasarım } \\
\text { İç Tasarım } \\
\text { Grafik } \\
\text { Moda } \\
\text { Mücevherat } \\
\text { Oyuncak } \\
\text { Yaratıcı } \\
\text { Hizmetler } \\
\text { Mimari } \\
\text { Reklamcılık } \\
\text { Yaratıcı } \\
\text { Arastırma ve } \\
\text { Geliştirme } \\
\text { Kültürel } \\
\text { Hizmetler } \\
\text { Dijital Hizmetler } \\
\text { vb. }\end{array}$ & $\begin{array}{l}\text { İlişkili Kültür } \\
\text { Endüstrileri } \\
\text { Reklamcilık } \\
\text { Mimari } \\
\text { Tasarım } \\
\text { Moda }\end{array}$ & $\begin{array}{l}\text { Kısmi Telif } \\
\text { Hakları } \\
\text { Endüstrileri } \\
\text { Mimari } \\
\text { Giyim } \\
\text { Ayakkabı } \\
\text { Tasarım } \\
\text { Moda } \\
\text { Ev Eşyaları } \\
\text { Oyuncaklar }\end{array}$ & $\begin{array}{l}\text { Baskı } \\
\text { Teknolojileri } \\
\text { Yazılım } \\
\text { Teknolojileri } \\
\text { Görsel İşitsel } \\
\text { Malzemeler }\end{array}$ \\
\hline
\end{tabular}

Tablo 1 içerisinde de yer aldığı üzere, yaratıcı endüstriler ekosistemi kapitalizmin bilişsel koşulları içerisinde yeniden keşfedilen oldukça geniş bir bağlamı işaret etmekle birlikte böylesi bir uzamın girişimcilik üzerine geliştirdiği vurgu ile de geleneksel girişimciliğe göre ayrımlaştığ 1 belirtilmelidir. Yaratıcı endüstriler içerisinde, girişimciliğin tam da ayırt edici boyutunu sözü edilen ayrım oluşturmaktadır. Geleneksel girişimcinin "gelişme yönelimli” olan eğilimi ile yaratıcı girişimcinin "yaratıcı yönelimli” eğilimi arasındaki gerilimdir. Bu doğrultuda, yaratıcı girişimcinin öncelikli amacının kendisini gerçekleştirme ya da düşüncelerini uygulamaya sunabilmesi olduğu, geleneksel girişimcinin ise önceliğinin gerçekleştirdiği girişimin mali değeri üzerine yoğunlaştığı belirtilebilir. John Howkins ${ }^{20}$ ise yaratıcı girişimcinin aslında Jean Baptiste Say’in bir öngörüsünü farklı açıdan yeniden ürettiğini tam da bu açıdan ileri sürer.

Howkins'e göre yaratıcı ekonomilerde girişimci, Say Kanununu farklı bir açıdan, yaratıcı fikirlerin daha fazla zenginlik yaratacağını öngörerek yeniden üretmektedir. Bununla birlikte yaratıcı girişimcinin kendisini gerçekleştirme sürecinde girişimini 
gerçekleştirdiği uzam ile ayırt edilebilir bir dizi teme niteliğine sahip olduğu söylenmelidir. Boix, Lazeretti ve Serra ${ }^{21}$, gelişmekte olan ülkelerde yaratıcı girişimciliğin "dolaylı etkileri" oldukça sınırlı tartışmaların odağında yer edinmiş olsa da, yaratıcı girişimciliği daha geniş ölçüde ülke ekonomileri ile bütünleştiren sürecin tam da sözü edilen "dolaylı etkiler" üzerinden ele alınmasının anlamlı olduğu söylenmelidir.

Tablo 2. Yaratıcı Girişimciliğin Türleri ve Temel Karakteristikleri ${ }^{22}$

\begin{tabular}{|c|c|c|}
\hline Yaratıcı Girişimci & Yaratıcı Uzam & Temel Karakteristiği \\
\hline $\begin{array}{l}\text { Yaratıcı Hizmet } \\
\text { Sağlayıcılı̆̆ı Girişimciliği }\end{array}$ & $\begin{array}{l}\text { Reklam Ajansları } \\
\text { Tasarım Danışmanlığı } \\
\text { Mimari Pratikler } \\
\text { Yeni Medya Ajansları }\end{array}$ & $\begin{array}{l}\text { Müşteriler için yaratıcı } \\
\text { hizmetleri sağlarlar } \\
\text { Kullanıcı talepleri } \\
\text { ile doğrudan temas } \\
\text { halindedir } \\
\text { Gelir elde ederler } \\
\text { Zamanlarını, fikri haklar } \\
\text { üretimleri için kullanırlar } \\
\text { Teknoloji ve } \\
\text { dijitalleşmeden yoğun } \\
\text { olarak etkilenirler } \\
\text { Genellikle proje } \\
\text { temellidirler } \\
\text { Genellikle özel girişimler } \\
\text { olup kendi kendilerini } \\
\text { finanse ederler. }\end{array}$ \\
\hline $\begin{array}{l}\text { Yaratıcı İçerik Sağlayan } \\
\text { Girişimler }\end{array}$ & $\begin{array}{l}\text { Film, televizyon ve tiyatro eseri } \\
\text { üreten şirketler } \\
\text { Bilgisayar ve oyun geliştirme } \\
\text { stüdyoları } \\
\text { Müzik şirketleri } \\
\text { Kitap ve dergi yayıncıları } \\
\text { Moda tasarımcıları }\end{array}$ & $\begin{array}{l}\text { Fikri hakka konu olan } \\
\text { eserler üretirler. } \\
\text { Yaratıcı projeleri } \\
\text { geliştirirler. } \\
\text { Genellikle proje } \\
\text { temellidir } \\
\text { Ön ödemeli sermaye } \\
\text { yatırımlarıdır. } \\
\text { Yaratıcılık ve kullanıcı } \\
\text { talepleri doğrultusunda } \\
\text { dijitalleşmeden yüksek } \\
\text { oranda etkilenirler. } \\
\text { Fonlama ve kendi } \\
\text { kendisini finanse etme } \\
\text { yönünde karma bir finans } \\
\text { yapıları bulunur. } \\
\text { Korsan üretimler ya da } \\
\text { rakip şirketlerden yoğun } \\
\text { olarak etkilenirler. }\end{array}$ \\
\hline
\end{tabular}

21 Rafael Boix, Lazeretti Luciana ve Daniel Sera Sanchez, "Entrepreneurship and Creative Industries in Developing and Developed Countries", Creative Industries and Entrepreneurship: Paradigms in Transition from a Global Perspective, der., Luciana Lazeretti ve Marilena Vecco, Paris: Edward Elgar Publishing, 2018, s.52.

22 Bujor ve Avasilcai, "Creative Entrepreneurship". 


\begin{tabular}{lll}
\hline $\begin{array}{l}\text { Yaratıcı Deneyim Sağlayan } \\
\text { Girişimler }\end{array}$ & Tiyatro, opera ve dans üretim & Tüketim için yer ya da \\
& şirketleri & zaman satarlar. \\
& Canlı müzik organizasyon & Hak sahiplerinin telif \\
& şirketleri & haklarını öderler. \\
& Seyirlik spor organizasyon & Genellikle sözleşme \\
& şirketleri & temellidirler. \\
& Festivaller & Tüketim ve iletişim aracı \\
Kültürel kurumlar & olarak dijitalleşmeyi \\
Turist organizasyon şirketleri & kullanırlar. \\
\hline Görsel Sanatlar & Eserlerinin kültürel \\
& Zanaatlar & değerleri tarafından \\
Tasartıcı Tür Üreten & ücretlendirilirler. \\
& Antikalar & Kitlesel üretim amaçları \\
& yoktur. Genellikle \\
& eserlerinin tek bir örneği \\
& ya da sinırlı sayıdaki ürün \\
& ve hizmetlere sahiptirler. \\
& Endüstriyel olmaktan \\
& daha çok sanat \\
& temellidirler. \\
\hline
\end{tabular}

Yukarıda Tablo 2 içerisinde yer aldığ üzere, yaratıcı girişimciliğin birbirinden önemli ölçüde ayrılan bir dizi ekosistem içerisinde yer edinmiş olması, aslında, bir yandan da yaratıcı girişimciliğe dair ilginin görünürlük edinmesini sağlamaktadır. Avrupa Birliği İstatistik Genel Müdürlüğü’nün gerçekleştirdiği AB üye ülkeleri içerisindeki kültür temelli girişimcilik araştırmasında yer aldığı üzere, kültür ve yaratıcı endüstriler ekosisteminin önemli bir istihdam ve refah kaynağ 1 olarak kayda değer bir alan olduğu belirlenmiştir. 2016 yılında 192 milyar Euro düzeyinde bir mali büyüklük üreten söz konusu ekosistemin istihdam potansiyeli ise belirgindir. Örneğin 2016 yılında 1 milyonun üzerindeki (1 milyon 200 bin) kültür temelli girişimci kültür temelli girişimin varlığı yalnızca iki yılın ardından, 2018 yılında, 8 milyon 700 bin kişiye genişleyen bir istihdam gerçekleştirmiş ve Avrupa Birliği içerisindeki toplam istihdamın \%3.8'ini tek başına gerçekleştiren bir ekosistem oluşturmuştur.

Avrupa Birliği'nin yaratıcı kültür endüstrileri ekosistemi içerisindeki kültürel istihdamı, Türkiye bu çalışmanın bir sonraki alt kısmından başlamak üzere ayrıntılı olarak ele alınacak olmasına rağmen bu kısım içerisinde en azından genel bir fikir verebilmesi için aşağıdaki Grafik 1 içerisinde $\mathrm{AB}$ üye ve aday ülkeleri arasında bir karş1laştırma yer almaktadır. Bununla birlikte henüz Grafik 1'in sunumuna geçilmesinin öncesinde önemli bir unsurun vurgulanması doğru olacaktır. Türkiye’nin Avrupa Birliği ile uzun süreli üyelik görüşmelerine rağmen söz konusu ekosistem içerisinde nerede ise Birliğin 28 ülke ortalamasına oldukça yakın bir istihdam potansiyeline sahip olduğu belirtilmelidir. 2018 yılı içerisinde Birliğin toplam istihdamı içerisinde \%3,8 ortalama değerinin yaratıcı kültür endüstrileri içerisinde yer almasına rağmen Türkiye'nin nerede ise \%3 düzeyine (2.9) yakın bir istihdam potansiyeli söz konusu ekosistem ve bileşenleri içerisinde elde edilmiştir. 


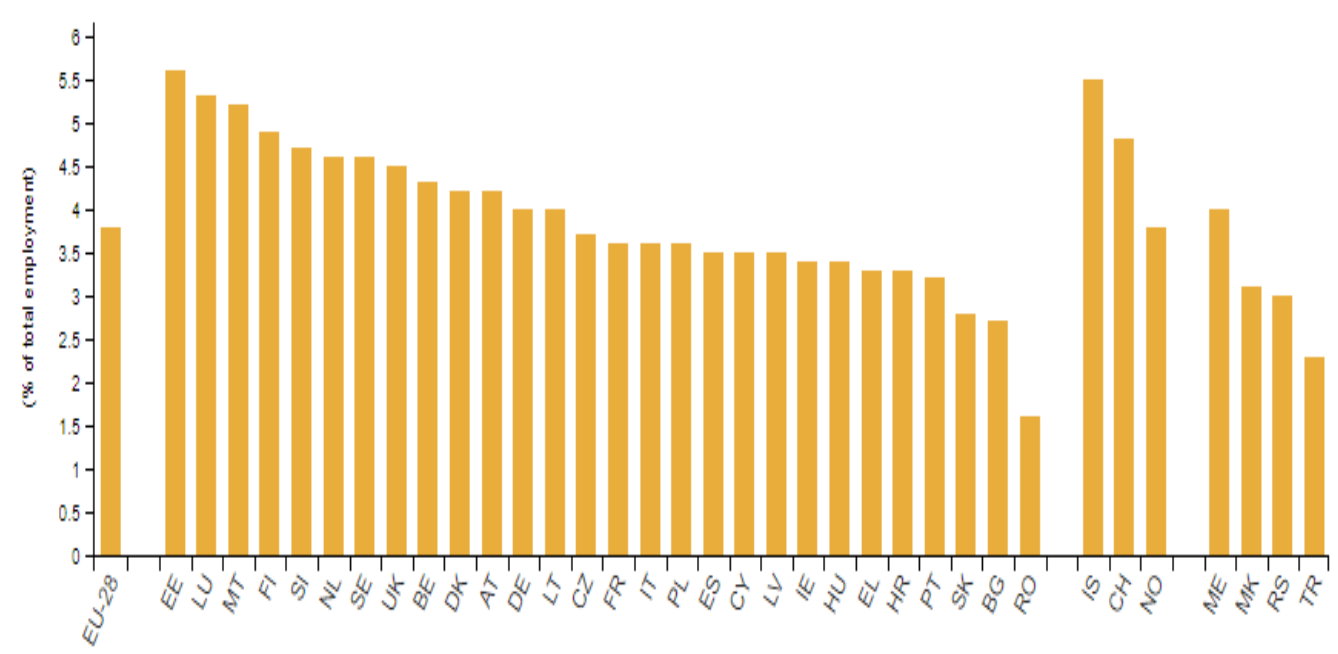

Grafik 1. AB Üye ve Aday Ülkelerinde Yaratıcı Kültür Endüstrileri İstihdam Oranlari ${ }^{23}$

Grafik 1 içerisinde yer aldığı üzere, Avrupa Birliği’nin Romanya dişında nerede ise bütün ülkelerinin yaratıcı kültür endüstrilerinde Birlik ortalamasının üzerinde yer aldığı görülür. Ancak, İspanya, Çek Cumhuriyeti ve Estonya’nın Birliğin söz konusu ekosistem içerisinde en fazla istihdam olanağı sağlayan ülkeler olduğu görülmektedir. Bununla birlikte böylesi bir farklılığın kapitalizmin bilişsel temelli uğrağı içerisinde söz konusu ülkelerin daha önde oldukları yönünde olmaları ile değil oldukça geniş bir uzama yayılan yaratıcı kültür endüstrilerinin örneğin turizm gibi bileşenleri üzerindeki istihdam potansiyeli üzerinden açıklanması doğru olacaktır. AB içerisinde mimari, tasarım ve fotoğrafçılık alanlarının kültür temelli girişimcilik ekosisteminin yarısından daha fazlasını oluşturmaktadır. Bununla birlikte AB içerisinde bir diğer önemli veri, küçük ve orta ölçekli girişimlerin kültürel ekonomileri yönlendirme gücüdür. Bununla birlikte bu çalışmanın giriş kısmından itibaren yer verildiği üzere sözü edilen kültür temelli girişimcilik ekosisteminin bir kültürel ekonomik coğrafya içerisindeki dağılımıdır. Aşağıdaki Grafik 1 içerisinde de yer verildiği üzere birbirine coğrafi olarak yakın AB üyesi ülkelerin kültür temelli girişim ekosistemi içerisinde birbirine oldukça yakın bir dağılım göstermesidir.

Yaratıcı kültür endüstrileri ekosistemi içerisinde yaratıcı endüstrilerin ülkeler için yeni refah ve istihdam kaynaklarını oluşturduğu nerede ise önemli bir uzayışı oluşturmakta iken söz konusu ekosistemin kültürel ekonomik coğrafya içerisinde yaratıcı endüstrilerin bir kümeleşme oluşturarak genişlemesi sınırlı sayıdaki çalışmanın odağında yer almaktadır. Oysa aşağıdaki Grafik 1 içerisinde yer aldığı ve çalışmanın Türkiye'de kültür temelli girişimlerin ayrıntılı olarak tartışılacağ 1 izleyen kısım içerisinde de değinileceği üzere yaratıcı kültür endüstrileri ekosistemi içerisindeki girişimcilik ancak ülkelerin böylesi bir alanda yer alma kararının ve izledikleri politikaların bir sonucu olarak değerlendirilmelidir.

23 Eurostat, “Culture Statistics-Cultural Entreprises”, 2019, çevrimiçi: https://www.ec.europe.eu/eurostat/about/ policies. 


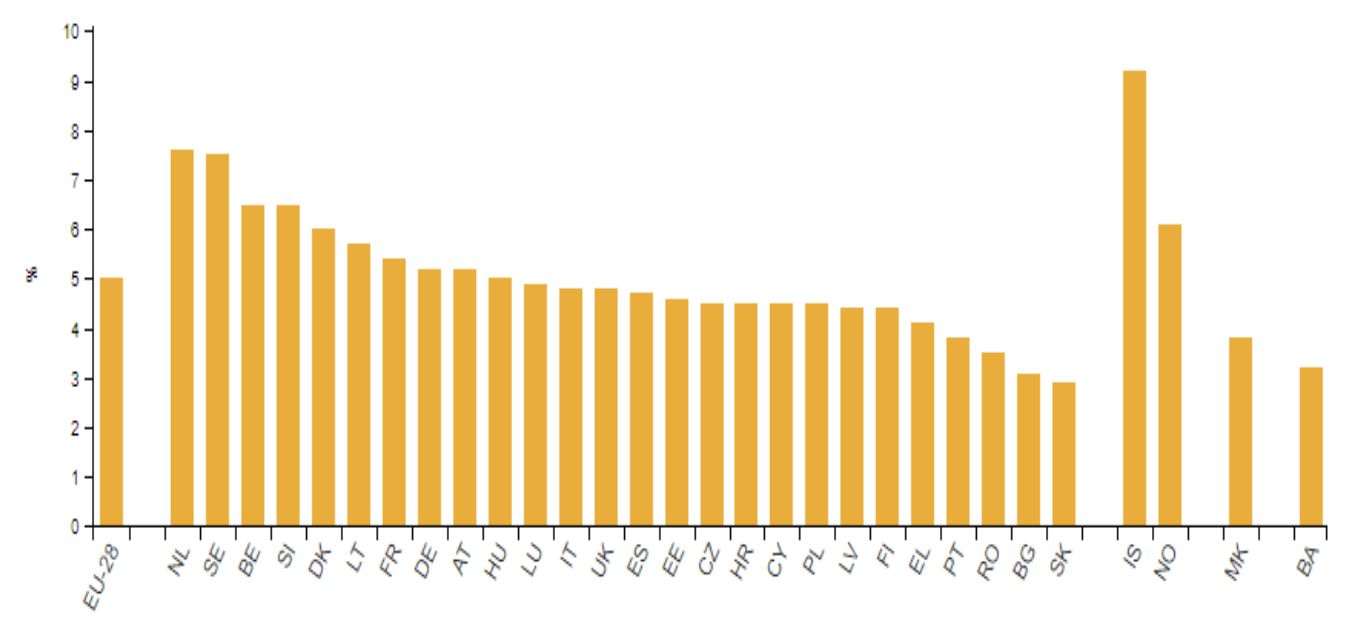

Grafik 2. Avrupa Birliği ve Aday Ülkelerinde Kültür Temelli Girişimcilik ${ }^{24}$

Grafik 2 içerisinde de yer aldığg üzere, Avrupa Birliği'nin kültürel temelli girişimcilik ve bileşen alt alanları içerisinde İspanya (\%10) ve Norveç'in (\%7) toplam girişimler içerisindeki ayırt edici varlıklarının dışında diğer ülkelerin AB genel ortalaması (\%5) içerisinde kaldığı (\%5 ile en yüksek \%7 olmak üzere) belirtilmelidir. Ancak Grafik 2 içerisinde de yer aldığ 1 üzere, birbirine coğrafi olarak yakın Birlik üyelerinin yine birbirine oldukça yakın bir girişim ağı oluşturduğu belirtilebilir. Ancak burada, AB’nin sahip olduğu ortak bir dizi kültür politikasının yanı sıra söz konusu üye ülkelerin ayırt edilebilir politikalara sahip olduğunun belirtilmesi gerekir.

Yaratıcı kültür endüstrileri ve bileşen alt alanları içerisinde küresel olarak kayda değer bir potansiyel oluşturan Türkiye'nin ise bir sonraki alt kısım içerisinden başlatılmak üzere kültür temelli girişimcilik ekosistemi içerisindeki varlığının incelenmesi ve Türkiye için bilgi toplumu kazanımlarından yararlanarak bir kültür politikasını nasıl geliştirebileceğinin tartışılması oldukça anlamlı olacaktır.

\section{Yaratıcı Kültür Endüstrileri Ekosistemi İçerisinde Türkiye}

$\mathrm{Bu}$ çalışmanın henüz giriş kısmından itibaren yaratıcı kültür endüstrileri ekosistemi içerisinde Türkiye’nin yalnızca kendi bölgesi içerisinde değil aksine küresel olarak ayırt edilebilir bir potansiyelinin olduğu vurgulanmıştı. Birleşmiş Milletler Ticaret ve Kalkınma Kongresi’nin ${ }^{25}$ "Yaratıcı Ekonomi” raporunda yer aldığı üzere Türkiye gelişmekte olan ülkelerin yaratıcı meta ihracatı içerisinde ilk 10 ülke arasında yer almaktadır. Raporda yer aldığı üzere, gelişmekte olan ülkelerin 2015 yılındaki ihracat değerleri aşağıdaki Tablo 3 içerisinde yer almaktadır.

Tablo 3. Yaratıcı Kültür Ekosistemi İçerisinde Gelişmekte Olan İlk 10 İhracatçı Ülke ${ }^{26}$

\begin{tabular}{|l|c|}
\hline Ülke İsmi & 2015 Yll İhracat Değeri $^{*}$ \\
\hline Çin Halk Cumhuriyeti & 168.507 \\
\hline
\end{tabular}

24 Eurostat, "Culture Statistics-Cultural".

25 UNCTAD, "Creative Economy".

26 UNCTAD, "Creative Economy”.

* Değerler, milyon Amerika Birleşik Devletleri Dolarını göstermektedir. 


\begin{tabular}{|l|c|}
\hline Hong Kong (Çin Halk Cumh. yön. kısım) & 27.872 \\
\hline Hindistan & 16.937 \\
\hline Singapur & 10.277 \\
\hline Tayvan & 8.671 \\
\hline Türkiye & 8.690 \\
\hline Tayland & 6.105 \\
\hline Malezya & 6.066 \\
\hline Meksika & 5.477 \\
\hline Filipinler & 1.010 \\
\hline
\end{tabular}

Tablo 3 içerisinde de görülebileceği üzere Türkiye’nin yaratıcı kültür endüstrileri ekosistemi içerisinde yer alan ilk 10 ihracatçı ülke arasında yer almasının yanı sıra, böylesi bir mali büyüklüğün bir bakıma kendi içerisinde bir sürekliliğe sahip olduğu söylenmelidir. Bununla birlikte, yaratıcı endüstriler ekosistemi içerisinde Türkiye’nin sürdürülebilir bir potansiyel oluşturmuş iken bu çalışmanın henüz giriş kısmından itibaren belirtildiği üzere kültürel yakınlığın Türkiye'nin yaratıcı kültür endüstrileri ekosistemi için oldukça kritik olduğu belirtilmelidir.

UNCTAD’ın" "Yaratıcı Ekonomi” raporunda yer aldığı üzere, Türkiye’nin 2014 y1lına kadar başat ticari "arkadaşlarını” Asya (\%54), Amerika (\%6) ve Avrupa (\%29) ülkeleri oluşturmakta iken, Türkiye’nin Avrupa Birliği ilişkilerinin bu tarihin ardından farklı bir siyasal eğilim izlemesi, bu kez önemli ticaret "ortaklarının” yakın bölge ülkeleriyle oluştuğu görülür. Ancak böylesi bir rota değişiminin ardından dahi Türkiye'nin yine de kültürel meta ihracatında Avrupa Birliği ortalamasının ve hatta üye ülkelerinin üstünde olduğu söylenmelidir. Grafik 3 içerisinde yer aldığı üzere, Türkiye Avrupa Birliği ortalamasının iki katı üstünde ve en yakın takipçisi olan İngiltere'nin toplam ihracatının üzerinde bir büyüklüğe 2017 yılında ulaşmıştır.

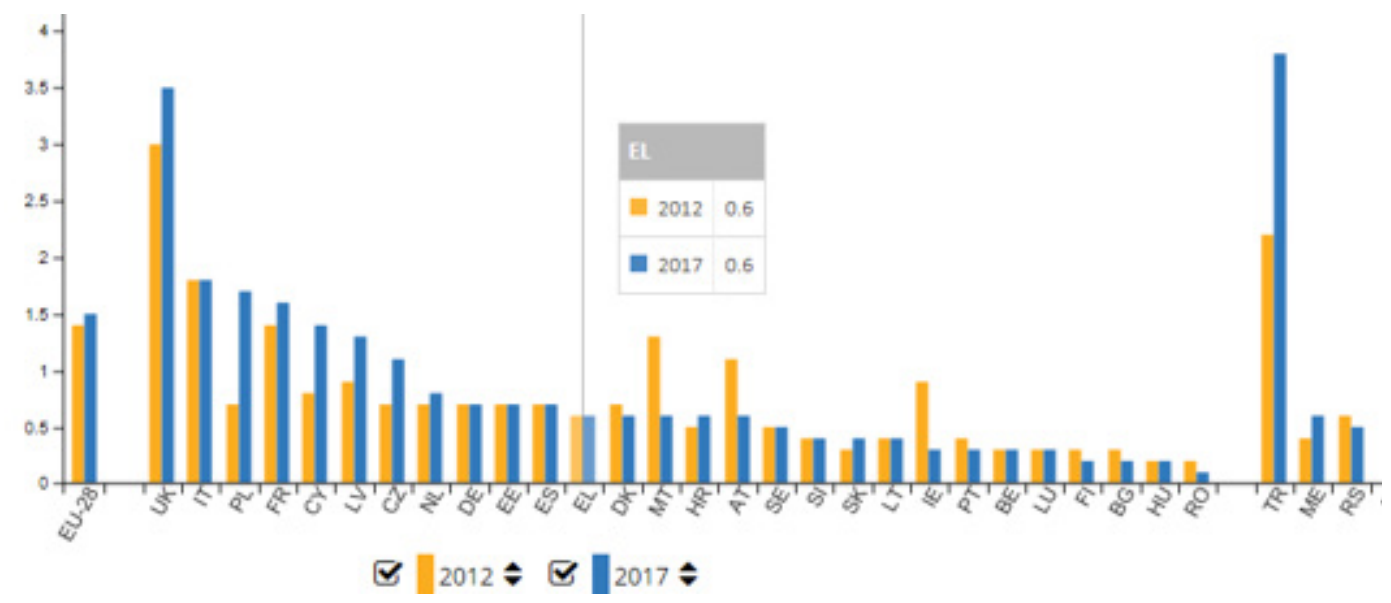

Grafik 3. 2012-2017 Yilları Arasında Türkiye ve Avrupa Birliği Ülkeleri Kültürel Meta İhracatt ${ }^{28}$

Türkiye’nin yaratıcı kültür endüstrileri ekosistemi içerisindeki mali "başarısının" 
ağırlıklı olarak yaratıcı uzamları oluşturan kentleri eliyle gerçekleşmiş olduğu belirtilmelidir. Bu açıdan Ankara, İstanbul ve İzmir’in bir yaratıcı uzam olarak değerlendirilmesi ile bilişsel kapitalizm döneminde sözü edilen kentlerin potansiyel girişimcilik niteliğinin değerlendirilmesi önem taşımaktadır.

\section{Yaratıcı Uzamlar Olarak Kentler: Ankara, İstanbul ve İzmir}

Kültür temelli yaratıcı girişimciliği anlamlandırmanın başat yollarından birisini, çalışmanın henüz girişinden itibaren ele alındığı üzere, yaratıcı uzamlar olarak kentlerin yeniden ancak bu kez farklı bir gözle değerlendirilmesi oluşturur. Bilgi temelli kapitalizmin dönüşümleri ile kentsel habitusun 1970'li yılların ardından geçirdiği değişim sürecinin birbirine refakat etmesi bir yana, bilgi temelli kapitalizmin ihtiyaç duyduğu üretimin tam da dönüşen kentsel habituslar içerisinde biçimlendirilmesi yukarıda sözü edildiği üzere kültür temelli girişimciliğin anlamlandırılabilmesi adına özel bir uğrağı oluşturmaktadır. Bu doğrultuda, çalışmanın bu alt kısmından başlamak üzere yaratıcı "girişim” uzamları olarak Ankara, İstanbul ve İzmir özelinde Türkiye’nin kültür temelli girişimcilik ekosisteminin değerlendirilmesi anlamlı olacaktır. Bununla birlikte, yukarıda yer alan Tablo 1 içerisinden de görülebileceği üzere, yaratıcı kültür endüstrilerinin oldukça geniş bir uzamı oluşturmasına rağmen bu çalışmanın kültür temelli girişimcilik uzamını tartışma odağına alması nedeni ile çalışmanın bu alt kısmının bir dizi açıdan sınırlandırılmasının gerekliliği söylenmelidir.

Yaratıcı kültür endüstrileri ekosisteminin, henüz giriş kısmından itibaren ele alınd1ğı üzere, bilgi toplumuna dönüşüm süreci içerisinde doğmuş olması çalışmanın bu kısmının bilgi toplumu ve bilişsel kapitalizm içerisinde görünürlük edinen kültür temelli girişimcilik potansiyeli ile sınırlandırılmış olduğu belirtilmelidir. Bu doğrultuda Ankara, İstanbul ve İzmir'in her ne kadar girişimcilik potansiyeli yalnızca bilgi toplumunun önemli bir bileşeni olarak kapitalizmin yeni uğrağ ile sınırlandırılamayacak olmasına rağmen, çalışma bilgi toplumu dönüşüm süreçleri içerisinde sözü edilen üç kenti tam da bilişsel alt yapısı bağlamında odağına almaktadır.

Yaratıcı kültür endüstrileri ekosistemi içerisinde yukarıda yer alan kentlerin kültür bağlamlı bir girişimcilik tartışması içerisinde yer alması için oldukça güçlü nedenler bulunmaktadır. O denli ki, birbirinden farklı ölçeklerdeki kalkınmışlık düzeyleri ve gelişim için ayırt edilebilir önceliklere sahip olmalarına rağmen, kültür temelli girişimciliğin kentsel mekânları içerisinde yer edindiği kentsel deneyimlerin söz konusu şehirlerde gelişmesi bir yana, yaratıcı kültür endüstrileri ekosistemi içerisindeki farklı yeterlilik düzeyleri sözü edilen kentleri öne çıkartmaktadır. Aşağıdaki Grafik 4 içerisinden de görülebileceği üzere, Türkiye'nin kültür temelli girişimlerinin söz konusu kentlerde yoğunlaştığ 1 görülmektedir.

Kentsel habitus içerisinde İstanbul ilk sırada, İzmir’in ikinci ve Ankara’nın üçüncü sırada yer almasına karşın, yaratıcı kültür endüstrileri bileşenleri içerisinde, örneğin araştırma geliştirme olanakları ile bilgi teknolojilerinin kullanımı öncelikli olmak üzere, farklı ağırlıklara sahip olduğu belirtilmelidir. Örneğin İzmir her ne kadar kül- 
tür eksenli girişimcilik ekosisteminde, işyeri sayısı olarak, ikinci sırada yer alsa da sivil toplum bileşenleri tarafından yaratıcı kültür endüstrilerine ilişkin yoğun bir ilginin yöneltildiği belirtilmelidir. Yerel bir öncelik olarak kurulan "İzmir Yaratııı Endüstriler Platformu" kentin yaratıcı endüstriler ekosistemi içerisindeki farkındalık bilincini ortaya koyarken gerçekte bir başka süreci daha işaret etmektedir. Bununla birlikte böylesi bir unsuru açılkayabilmek için bir dizi girişimin birlikte değerlendirilmesi doğru olacaktır. O denli ki, Mayıs 2012 yılında İstanbul'da kurulan, moda ve tiyatro gibi söz konusu endüstrilerin geleneksel bileşenlerinin yer aldığı "Yaratıcı Endüstriler Konseyi Derneği”, 2012 yılında kurulan Ankara merkezli, TOBB ETU girişimcilik ekosistemi içerisinde kuluçka merkezi niteliğindeki "Garaj” uygulaması birlikte değerlendirilmelidir ${ }^{29}$. Yaratıcı kültür endüstrilerinin "toplumda ve toplum için” yenilikçiliğin merkezi unsurları olarak yalnızca ekonomik değil eş zamanlı bir biçimde toplumsal refah ve yaşam standartlarının geliştirilmesi ile toplumsal duyarlılık oluşturma "kavrayışı" yukarıda yer alan örneklerle birlikte öne çıkmaktadır. Böylesi bir açıdan bakıldığında Ankara, İstanbul ve İzmir' in kültür temelli girişimcilik ekosistemi içerisinde diğer kentlere göre önemli bir yoğunlaşma deneyiminin nedenleri anlaşılmaktadır.

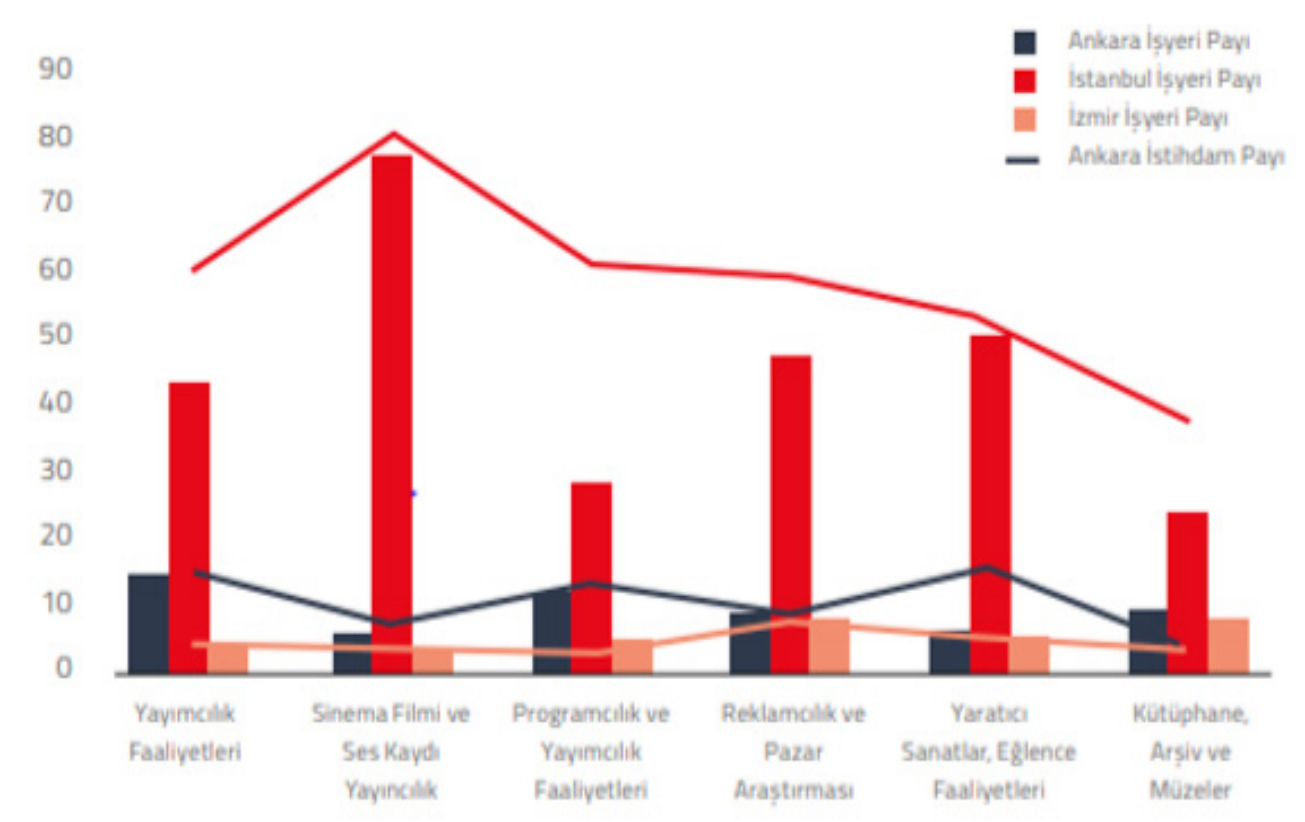

Grafik 4. Kültür Temelli Girişimcilik İçerisinde Ankara, İstanbul ve İzmir Karşılaştırmasi ${ }^{30}$

Grafik 4 içerisinden görülebileceği üzere, araştırmanın odaklandığı kentlerin kültür temelli girişimcilik ekosistemi içerisinde ağırlıklı olarak sinema, film ve ses kaydığı yayıncılığı, yaratıcı sanatlar ve eğlence faaliyetleri ile reklamcılık ve pazar araştırması olmak üzere 3 temel bileşen üzerinde yoğunlaştı̆̆ görülmektedir. Bununla birlikte, yukarıdaki Tablo 1 içerisinde yer aldığı üzere yaratıcı kültür endüstrilerinin, üstelik

29 TOBB ETU, “Girişimciye Garaj Deneyimi TOBB ETU’de”, https://www.etu.edu.tr/tr/bolum/uluslararasigirisimcilik/haber/girisimciye-garaj-deneyimi-tobb-etu-de.

30 Ankara Kalkınma Ajansı, “2014-2023 Ankara Bölge Planı”, 2013, s.62, (erişim 18.10.2020). 
bilgi temelli kapitalizm ve değişen iş modelleri ile birlikte düşünüldüğünde, önemli bir bileşeninin teknoloji ve teknolojinin kullanılması üzerinden yenilikçilik alanlarının üzerine kurulduğu belirtilmelidir. Ancak böylesi bir ekosistem içerisinde Türkiye’nin teknolojiyi kullandığı kadar üretemeyen bir ülke olduğu üstelik bizatihi Kalkınma Ajansları olmak üzere resmi otoriteleri tarafından da belirlenmiştir. Örneğin İstanbul Kalkınma Ajansı’nın ${ }^{11 ~ " T u ̈ r k i y e ~ G i r i s ̧ i m c i l i k ~ E k o s i s t e m i ~ F i n a n s a l ~ D e s t e k l e r ~}$ ve Mevcut Durum” raporunda yer aldığı üzere "Türkiye, teknolojiyi üretme, küresel ölçekte internet ve/veya teknoloji girişimleri çıkarma konusunda teknolojiyi bünyesine adapte ettiği kadar iyi değildir". Ancak, böylesi bir "iyi olmama” halinin somut ifadesi, özellikle yaratıcı kültür endüstrileri ve girişimcilik ekosistemi dikkate alındığında, Türkiye’nin bilgi toplumuna dönüşüm sürecinin kazanımlarından yararlanamayan bir ülke görünümünü öne çıkartmaktadır. Türkiye yukarıda ele alındığı üzere yaratıcı endüstriler ve bileşen alt kümeleri dikkate alındığında küresel olarak dikkat çeken bir ülke olmasına rağmen internet temelli, ticari değeri bir milyar doların üzerindeki, "unicorn” şirketlerin ekonomiye eklemlenemediği bir matrisi öne çıkartmaktadır.

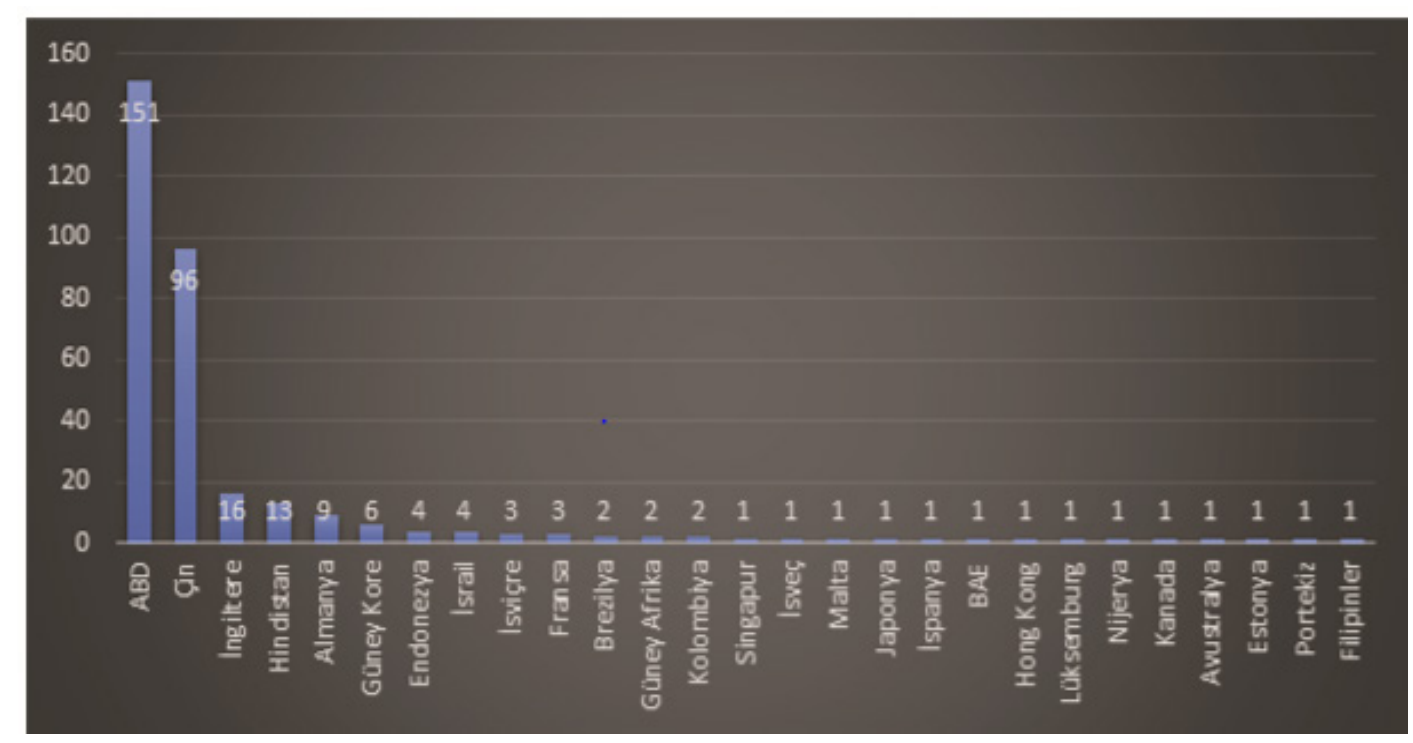

Grafik 5. Küresel Ölçekte İnternet Temelli Şirketlere Ev Sahipliği Yapan Ülkeler

Yukarıdaki Grafik 5 içerisinde alıntılandı̆̆ı İstanbul Kalkınma Ajansı’nın ${ }^{32}$ verilerinden yola çıkıldığında küresel düzeyde 1 milyar dolara ulaşan mali büyüklüğü ile internet temelli şirketlerin ev sahibi olarak Amerika Birleşik Devletleri’nin (151), Çin Halk Cumhuriyeti'nin (96), İngiltere'nin (16), Hindistan (13) ve Avusturyànın (9) öne çıktığg görülmektedir.

Türkiye'nin yaratıcı endüstriler ekosistemi içerisindeki küresel olarak ayırt edilebilir potansiyeline rağmen, kapitalizmin bilişsel uğrağ içerisinde yenilikçilik ağını kurma potansiyeli olan "unicorn” şirketlerini henüz geliştirmemiş olması gerçekte bilişsel

31 İstanbul Kalkınma Ajansı, “Türkiye Girişimcilik Ekosistemi Finansal Destekler ve Mevcut Durum”, 2019, s.71, (erişim 31.10.2019).

32 İstanbul Kalkınma Ajansı, “Türkiye Girişimcilik”, s.5. 
kapitalizmin olanaklarından yararlanamayan bir ülke olmasına yol açmaktadır. Bu doğrultuda, yaratıcı girişimcilik ekosisteminin Türkiye’de geliştirilebilmesine dair bir dizi önerinin geliştirilmesi anlamlı olacaktır.

\section{Sonuç: Bulgular ve Değerlendirme}

Ülkelerin yeni refah ve istihdam kaynakları olarak öne çıkan yaratıcı endüstriler içerisinde kentler ve ekonominin geniş bağlamı arasındaki diyalektiğin özel bir uğrağının tam da yeni bir girişimcilik üzerinde yükseldiği söylenmelidir. Yaratıcı girişimciliğin, yukarıda da vurgulandığı gibi, tek başına piyasalar içerisinde yeni metaları oluşturan bu doğrultuda üretim ilişkilerini bir bakıma yeniden düzenleyen ve yeni bir ilişkiler ağı içeresinde son kertesinde kâr elde etmeyi amaçlayan iş aktörleri olmaktan daha çok farklı bir eksen üzerinden bakılarak tanımlanmasını gerektiren boyutları bulunmaktadır. Egemen siyasanın, örneğin yukarıda ele alındığı üzere Avrupa Birliği’nin, 2000 yılının ardından yaratıcı endüstriler içerisindeki siyasa geleneğinin başat unsurunu tam da böylesi bir yenilikçilik ağının oluşturulması üzerinden geliştirmesi, en azından, bir rastlantı ile açıklanamayacak denli açık bir biçimde görülmektedir. Bununla birlikte, gelişmiş ülkeler ya da Birleşmiş Milletler, Avrupa Parlamentosu gibi ulus üstü örgütlenmeler eliyle geliştirilen yaratıcı girişimcilik politikalarının yanı sıra özellikle gelişmekte olan ülkelerin yapısal ihtiyaçları ile uyumlu girişimcilik politikalarını geliştirmesinin bir ihtiyaç olduğu belirtilmelidir. O denli ki, söz konusu ihtiyaç yalnızca bilgi toplumu koşulları içerisinde kamu politikalarına açık bir biçimde ihtiyaç duyan yaratıcı endüstriler ekosisteminin değil aksine ülkelerin yenilikçilik ve yaratıcı potansiyellerini güçlendirerek ülke ekonomilerinin kırılgan bir yapıdan çıkartılması ve güçlü, toplumun geniş kesimlerine istihdam sunabilen ve küresel düzeyde söz sahibi ülkelerin oluşmasınpı sağlayacaktır. Bu doğrultuda, bu çalışmanın yazımı devam ederken küresel düzeyde tanık olunan COVID 19 salgını ile yaratıcı girişimcilik arasındaki ilişkinin, en azından genel olarak, tartışılmasının anlamlı olduğu düşünülmektedir.

Yaratıcı endüstriler ekosisteminin ilk siyasalarını belirginleştiren İngiltere’nin kamu ve özel sektörleri arasındaki ittifakın sonucunda ortaya çıkmış olan İngiltere Yenilikçilik Vakfı'nın (NESTA) ${ }^{33}$ yakın dönemli çalışmasında yer aldığ üzere, küresel salgın dönemi ekonominin bütün bileşenleri için önemli ölçüde işsizlik ve iflas tehdidine yol açmış olsa da yaratıcı endüstrilerin böylesi bir "tehlikenin” uzağında kalabilme potansiyelenin daha yüksek olduğu görülmektedir. Ancak sözü edilen ekosistemin, küresel salgın ve ardından bir potansiyel bir aşama olarak görülen küresel ekonomik kriz gibi güçlü etkilere sahip olan "sarsıntı" dönemlerinin de ortaya çıkarttığı gibi bir dizi yapısal gerekliliğin karşılanmasına yoğun ihtiyaç duymaktadır. Bu doğrultuda, Türkiye özelinde yaratıcı endüstriler ekosistemi için bir dizi önerinin geliştirilmesi anlamlidir.

Yaratıcı endüstrilerin istikrarlı birer ekonomik girişim olarak, gelişmekte olan ülkelerde de, ülkelerin yeni refah ve istihdam kaynakları haline getirilmesinin bir di-

33 Hasan Bakhshi, "Capturing the Impact of Covid-19 on the Creative Industries", Nesta, 31.03.2020, https:// www.nesta.org.uk/blog/capturing-impact-covid-19-creative-industries/. 
ğer ön koşulu ise toplumun geniş kesimlerinin yaratıcı endüstriler ile kurduğu bağ aracılığı ile sağlanacaktır. Türkiye'de toplumun geniş kesimleri ise böylesi bir bağın kurulabileceği yeterliliğe sahiptir.

\section{Kaynakça}

Alacovska, Ana ve Rosalind Gill. "De-Westernizing Creative Labour Studies: The Informality of Creative Work from an Ex-Centric Perspective". International Journal of Cultural Studies. 22/2 (2019): 195-212.

Ankara Kalkınma Ajansı. "2014-2023 Ankara Bölge Planı”. 2013. http://www.ankara. org.tr/ankara.bolgeplanı. (erişim 18.10.2020).

Bakhshi, Hasan. "Capturing the Impact of Covid-19 on the Creative Industries". Nesta. 31.03.2020. https://www.nesta.org.uk/blog/capturing-impact-covid-19creative-industries/.

Bhansing, V. Pawan, Erik Hitters ve Yosha Winjgarden. "Passion Inspires: Motivations of Creative Entrepreneurs in Creative Business Centers in the Netherlands". The Journal of Entrepreneurship. 27 / 1 (2019): 1-24.

Boix, Rafael, Luciana Lazeretti ve Daniel Sera Sanchez. "Entrepreneurship and Creative Industries in Developing and Developed Countries". Creative Industries and Entrepreneurship: Paradigms in Transition from a Global Perspective. Der., Luciana Lazeretti ve Marilena Vecco. Paris: Edward Elgar Publishing, 2018: $35-$ 57.

Bujor, Adriana ve Silvia Avasilcai. "Creative Entrepreneurship in Europe: A Framework of Analysis". Annals of the Oradea University: Fascicle of Management and Technological Engineering. 1 (2014): 151-156.

Eurostat. "Culture Statistics-Cultural Entreprises". 2019. https//www.ec.europe.eu/ eurostat/about/policies.

Fuchs, Christian. “Kapitalizm mi? Enformasyon Toplumu mu?”. Dijital Emek ve Karl Marx. Çev., Tahir Emre Kalaycı ve Senem Oğuz. Ankara: NotaBene Yayınları. 2015: 203-225.

Gov.Uk. "Creative Industries Economic Estimates". 2019. http://www.gov.uk/ collections/creativeindustrieseconomicestimates.

Hesmondhalgh, David, Kate Oakley, David Lee ve Melissa Nisbett. Culture, Economy and Politics: The Case of New Labour. Basingstoke, Hampshire: Palgrave \& McMillan Publications, 2015.

HKU. The Entrepreneurial Dimensions of the Cultural and Creative Industries. Utrecht: Hogerschool vor de Kunsten Publications, 2010.

Howkins, John. The Creative Economy: How People Make Money from Ideas. New York: Penguin Books. 2001.

İstanbul Kalkınma Ajansı. “Türkiye Girişimcilik Eko-sistemi Finansal Destekler ve Mevcut Durum”. 2019. https://www.istka.org.tr/media/131459/türkiyegirişimcilik-eko-sistemi-mevcut-durum-raporu.pdf. (erişim 31.10.2019). 
Jin, Dal Yong. New Korean Wave: Transnational Cultural Power in the Age of Social Media. Chicago, Springfield: University of Illinois Press, 2016.

Kaymas, Serhat. "Yaratıcı Endüstriler Ekosistemi İçerisinde Ankara: Sorunlar, Olanaklar ve Potansiyeller Üzerine Bir Değerlendirme". Ankara Üniversitesi Sosyal Bilimler Enstitüsü Dergisi. 10/2 (2019): 108-125.

Kerrigan, Susan ve Samuel Hutchinson. "Regional Creative Industries: Transforming the Steel City into a Creative City in Newcastle, Australia". Creative Industries Journal. 9/2 (2014): 116-129.

Lazeretti, Luciana, Francesko Capone ve Erdem Seçilmiş. "In Search of a Mediterranean Creativity: Cultural and Creative Industries in Italy, Spain and Turkey”. European Planning Studies. 24/3 (2016): 568-588.

Lee, Hye-Kyung. "The Political Economy of Creative Industries". Media, Culture \& Society. 39/7 (2017): 1078-1088.

Lorenzo, Lucia Garcia, Paul Donelly, Lucia Sell-Trujillo ve J. Miguel Imas. "Liminal Entrepreneuring: The Creative Practices of Nascent Necessity Entrepreneurship". Organization Studies. 39/2-3 (2018): 373-395.

Saka, Erkan. "Dijital Dönüşüm ve Gazetecilik İçin Yeni İş Modelleri”. Dijitalleşen Gazetecilik İçin Yeni İş Modelleri. Der., Erkan Saka, Vehbi Görgülü ve Anıl Sayan. İstanbul: Taş Mektep Yayınları, 2017: 11-41.

Svarc, Jadranka. "The Knowledge Worker is Dead: What About Professions?". Current Sociology. 64/3 (2016): 392-410.

Thiel, Joachim. "Creative Cities and the Reflexivity of the Urban Creative Economy". European Urban and Regional Studies. 24/1 (2017): 21-34.

Throsby, David. "Modelling the Cultural Industries". International Journal of Cultural Policy. 14/3 (2008): 217-232.

Tiryakioğlu, Murad. “Schumpeter, Yenilik ve Yaratıcı Yıkım”. İktisadiyat. 18.03.2009. http://www.iktisadiyat.com/2009/03/18/schumpeter-yenilik-ve-yaratici-yikim/.

TOBB ETU. “Girişimciye Garaj Deneyimi TOBB ETU'de". https://www.etu.edu.tr/tr/ bolum/uluslararasi-girisimcilik/haber/girisimciye-garaj-deneyimi-tobb-etu-de.

UNCTAD. "Creative Economy Outlook: Trends in International Trade in Creative Industries: 2002-2015”. Erişim 18 Ekim, 2020, https:/unctad.org/system/files/ official-document/ditcted2018d3_en.pdf.

UNESCO. Creative Economy Report 2013 SpecialEdition: WideningLocal Development Pathways. New York, Paris: United Nations Development Programmes Publication, 2015.

WIPO. “How to Make a Living in the Creative Industries?". Geneva, 2017. https://www. wipo.int/edocs/pubdocs/en/wipo_pub_cr_2017_1.pdf. (erişim 18.10.2020).

Yamamura, Sakura ve Paul Laselle. "Proximities and the Emergence of Regional Industry: Evidence of the Liability of Smallness in Malta". European Planning Studies. 2019: 1-25.

Yum, Seungil. "The Relationship Between Creative Industries and the Urban Economy in the USA". Creative Industries Journal. 13/2 (2020): 95-116. 


\title{
Creative Industries, Culture-Based Entrepreneurship, and Critical Political Economy: Rethinking of the Blind Spot
}

SERHAT KAYMAS

\begin{abstract}
This study has endeavour to the rethinking of the transformations of culture-based entrepreneurships within Turkey's creative industries ecosystems. In the present study which is mainly based on "creative diffusions" and "cultural economic geography" theories; the culturebased entrepreneurships have almost been addresses the transformation process of knowledge based societies in Turkey. In the very close history of capitalism, culture-based entrepreneurship has emerged more than the meaning of solely commercial entrepreneurships, in this sense, this study aims to address an important component of Turkey's innovation network, Ankara, Istanbul and Izmir where the cities represent different sections of Turkey's creative ecosystem, has been chosen as the extent of the investigation. Istanbul, as well as being the European Capital in 2010, the UNESCO creative cities to take part in the design of the city's network of Ankara, Turkey's capital is in addition to the information technology field of creative urban transformation plan in Izmir with stand in for the selection of the city said provided an important justification. In the study, on the other hand, the entrepreneurship policies of UNESCO and the European Union in creative industries are evaluated through comparative policy analysis. At the end of the present study, a series of alternative governance models have offers for Turkey.
\end{abstract}

Keywords: Creative industries, Creative economy, Culture-Based entrepreneurship, Cultural geography, Creative diffusion 